\title{
Simulate methylation reaction of arsenic(III) with methyl iodide in an aquatic system
}

\author{
Baowei Chen, Thanh Wang, Bin He, Chungang Yuan, Erle Gao and Guibin Jiang*
}

State Key Laboratory of Environmental Chemistry and Ecotoxicology, Research Center for Eco-Environmental Sciences, Chinese Academy of Sciences, PO Box 2871, Beijing 100085, People's Republic of China

Received 4 May 2006; Accepted 25 June 2006

\begin{abstract}
The methylation reaction of inorganic arsenic occurring in aquatic systems was studied by HPLC-HGAFS as a method to separate and detect soluble methylarsenic species. Transformation from inorganic arsenic to methylarsenic was essential for major changes in toxicity to organisms. Monomethylarsenic $\left[\mathrm{AsOCH}_{3}(\mathrm{OH})_{2}\right.$ ] was the only product in the methylation reaction of inorganic arsenic(III) with methyl iodide (MeI). This process can be described as an oxidative carbonium-ion transfer, with MeI acting as a methyl donor. From a thermodynamic point of view, the activity of the carbonium ion and $\mathrm{pH}$ were the two major influencing factors. The $\mathrm{pH}$ dependence of redox potential of As(III) was the reason for the effect of $\mathrm{pH}$ on methylation of arsenic. The influences of salinity and concentration of the methyl donor may be explained by their effects on the activity of carbonium. Moreover, kinetics experiments demonstrated that the methylation reaction was first-order for both As(III) and methyl iodide. First-order reaction rates were also calculated at different $\mathrm{pH}$, salinity and $\mathrm{MeI}$, and were found to be in the range $0.0026-0.0123 \mathrm{~h}^{-1}$. The methylation rate varied largely under different reaction conditions. Copyright $\odot 2006$ John Wiley \& Sons, Ltd.
\end{abstract}

KEYWORDS: methylation; methyl iodide; inorganic arsenic; reaction kinetics; methylarsenic; aquatic environment

\section{INTRODUCTION}

Arsenic compounds are used widely as biocides or preservatives and released into the environment as a byproduct of industrial processes such as mining, smelting and fossil-fuel combustion. ${ }^{1}$ Owing to their increased levels in the environment and their well-known toxicity to animals and human beings, arsenic compounds are of great concern. Arsenic exposure via drinking water has been reported in many countries, such as West Bengal and India, where the groundwater was polluted by arsenic at high levels. ${ }^{2}$

As an important transformation and transportation pathway of arsenic, methylation of arsenic has been widely studied. During the late 1930s and 1940s, Challenger demonstrated

\footnotetext{
${ }^{*}$ Correspondence to: Guibin Jiang, State Key Laboratory of Environmental Chemistry and Ecotoxicology, Research Center for Eco-Environmental Sciences, Chinese Academy of Sciences, P.O. Box 2871, Beijing 100085, People's Republic of China.

E-mail: gbjiang@rcees.ac.cn

Contract/grant sponsor: National Natural Science Foundation of China; Contract/grant number: 20477053

Contract/grant sponsor: National Basic Research Program of China; Contract/grant number: 2003CB415001, 2005CB422206.
}

that toxic 'Gosio Gas', trimethylarsine, could emanate from damp wallpapers laden with arsenic-containing pigments., Research has indicated that the ability to produce methylarsine is widespread amongst yeasts, fungi, algae, animals, plants, bacteria and even humans. For example, McBride et al. proved that anaerobic methane bacteria can synthesize dimethylarsine; ${ }^{5}$ Arsenic oxide can be methylated by fungi from sewage (C. humicola and S. brevicaulis) to yield trimethylarsine and small amounts of monomethylarsine. ${ }^{6}$ Burrowing organisms (Nereis succinea, Macoma balthica, and Micrura leidyi) transport arsenic out of contaminated sediments with trace amounts of methylated arsenic compounds. ${ }^{7}$ Braman and Foreback reported the occurrence of non-volatile methylarsonate and dimethylarsonate in many environmental samples, including seashells, eggshells, natural waters and human urine. ${ }^{8}$ All such studies have shown that biological methylation is an important methylation pathway of arsenic.

Besides biomethylation, other studies have demonstrated that photochemical methylation of inorganic elements also exists as a parallel process in the environment. Akagi et al. demonstrated that it is possible for methylmercury to be produced by pure chemical reactions in natural environments 

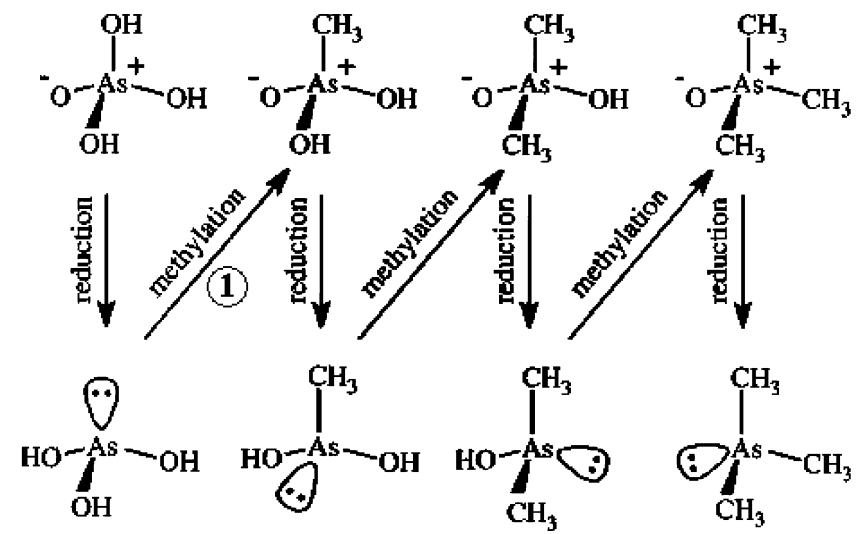

Figure 1. Schematic of the Challenger mechanism for arsenic methylation.

under the influence of sunlight. ${ }^{9,10}$ Similarly, volatile and nonvolatile alkyl-arsenic species can also be yielded through chemical reaction of acetic acid, propionic acid and butyric acid under ultraviolet irradiation. ${ }^{11,12}$ Moreover, chemical methylation of elements like tin and mercury may also occur in natural conditions with exocellullar methylating agents such as methylcobalamin and methyl iodide. ${ }^{13,14}$ However, there are few reports on chemical methylation of arsenic.

In a previous study, a mechanism was proposed for how methylation reactions of arsenic occur in natural environments. ${ }^{15}$ The methylation mechanism, shown in Fig. 1, consists of alternating sequences of reductive and oxidative methylation. The thermodynamic plausibility of arsenic methylation was predicted using quantum chemical methods. ${ }^{16}$ Although much effort has been made to understand methylation of the elements in natural environment, some aspects of methylation remain largely unknown, such as the major transformation pathway, other methyl donors, methylation pathway and so on. Thus, additional researches in this field are needed.

The first methylation step, from inorganic arsenic to methylarsenic, is very important for radical change of the toxicity of arsenic compounds. Methyl iodide exists widely in the aquatic environment, and is easily produced by macro algae and kelp. ${ }^{17,18}$ Therefore, methyl iodide was used as the model of methyl donor to study the methylation reaction from inorganic arsenic to methylarsenic in aquatic systems in this paper. The influences of three important factors, $\mathrm{pH}$, concentration of methyl donor and salinity, on arsenic methylation in the aquatic environment, were taken into account and kinetic experiments of methylation reaction were carried out.

\section{EXPERIMENTAL SECTION}

\section{Materials}

All reagents were obtained commercially and used without further purification unless otherwise stated. Standards of monomethylarsenic acid were obtained from Sigma Chemical Company (USA). Iodomethane (99.5\%) was purchased from Phentex Corp. (USA). Sodium arsenite (95\%) was obtained from Beijing Chemical Factory (China).

\section{Experiment design}

In general, methylation reactions took place in darkness at about $30^{\circ} \mathrm{C}$ using $50 \mathrm{ml}$ aqueous solutions in $100 \mathrm{ml}$ vials sealed with septa. For all experiments, $100 \mu \mathrm{lof} 2.5 \mathrm{mg} \mathrm{ml}^{-1}$ $\mathrm{Na}_{2} \mathrm{AsO}_{3}$ stock solution in $2 \mathrm{moll}^{-1} \mathrm{HCl}$ were used as inorganic arsenic source. The $\mathrm{pH}$ value of the reaction system was adjusted using $0.1 \mathrm{~mol}^{-1} \mathrm{NaOH}$ and $0.1 \mathrm{~mol} \mathrm{l}^{-1} \mathrm{HCl}$, and was determined using a $\mathrm{pH}$ meter (Hanna Instruments pH211C and HI 1200B glassbody combination pH electrode). The salinity of the solutions was adjusted with $5 \mathrm{~mol}^{-1} \mathrm{NaCl}$. In order to prevent As(III) becoming oxidized to As (V) by dissolved oxygen in the solution, the reaction system was placed in an ultrasonic bath to degas it and nitrogen bubbled through the solution. The dark condition was achieved by covering the reactor with aluminum foil. Reaction vials were always sealed under nitrogen atmosphere after adding the required reagents. Kinetic experiments were performed by analyzing the water solution sampled from reaction system at different times. Hydrogen peroxide was added to terminate the methylation reaction of inorganic arsenic.

\section{Analytical method}

An HPLC-HG-AFS coupling system was used to detect different arsenic species in the water. This method was evaluated by Yuan. ${ }^{20}$ A quaternary pump (P680 HPLC Pump, Dionex, USA) equipped with a Rheodyne Model $7715 \mathrm{i}$ injector valve (Rheodyne, Cotati, CA, USA) and a $20 \mu 1$ sample loop was used. An anion-exchange column (PRP$100,250 \times 4.0 \mathrm{~mm}$ i.d., Hamilton, USA) equipped with a guard column (IonPac AG11, Dionex, USA) was used to separate arsenic species. The fluent from the column was carried by $10 \% \mathrm{HCl}$ solution and mixed and reacted with $2 \% \mathrm{KBH}_{4}$ solution in a T-cross valve. Then, the gas-liquid mixture was separated using a gas-liquid separator. After separation by the second gas-liquid separator, arsenic compounds in the gas phase were carried into the atomizer by argon and detected using a AFS-610A atomic fluorescence spectrophotometer (Beijing Ruili Analytical Instrument Co., Beijing, China). A computer fitted with the AFS610 software was required for the control of the AFS and the integration of the peak areas. The column, T-cross valve and the gas-liquid separator were connected by a PTFE tube. Detailed experiment conditions for HPLC-HG-AFS were listed in Table 1.

\section{RESULTS AND DISCUSSION}

The HPLC-HG-AFS system was used to identify the products of methylation reaction in the aquatic environment. Figure 2 showed the chromatographs of reaction products 
Table 1. Experiment conditions for HPLC-HG-AFS

HPLC

Column Dionex IonPac AG11 guard column

$45 \times 4.0 \mathrm{~mm}$ i.d.

Hamilton IonPac PRP-100 column

$250 \times 4.0 \mathrm{~mm}$ i.d.

Mobile phase $\quad \mathrm{A}, \mathrm{H}_{2} \mathrm{O} ; \mathrm{B}, 50 \mathrm{mmol} \mathrm{L}^{-1}$ phosphate

buffer solution $\left(50 \mathrm{mmol} \mathrm{L}^{-1} \mathrm{Na}_{2} \mathrm{HPO}_{4}\right.$ and $50 \mathrm{mmol} \mathrm{L}^{-1} \mathrm{KH}_{2} \mathrm{PO}_{4}$ )

$0-5 \min , 95 \%$ A, 5\% B

5-6 min, from 95 to $0 \% \mathrm{~A}$, from 5 to

$100 \%$ B

6-10 $\min , 100 \%$ B

10-11 min, from 0 to $95 \% \mathrm{~A}$, from 100

to $5 \% \mathrm{~B}$

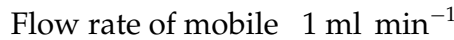

Injection volume $20 \mu \mathrm{l}$

\section{Hydride generation}

\begin{tabular}{ll}
\hline $\mathrm{KBH}_{4}$ & $2.0 \%(\mathrm{~m} / \mathrm{v}), 4 \mathrm{ml} \mathrm{\textrm {min } ^ { - 1 }}$ \\
$\mathrm{HCl}$ & $10.0 \%(\mathrm{v} / \mathrm{v}), 1 \mathrm{ml} \mathrm{\textrm {min } ^ { - 1 }}$
\end{tabular}

\section{AFS}

Lamp

PMT voltage

Hollow cathode arsenic lamp, $193.7 \mathrm{~nm}$

Primary current

Assistant current

$270 \mathrm{~V}$

$60 \mathrm{~mA}$

$30 \mathrm{~mA}$

Carrier gas

Argon, $500 \mathrm{ml} \mathrm{min} \mathrm{m}^{-1}$ and standard substances. It could be seen that several different water-soluble arsenic species can be separated successfully using the HPLC-HG-AFS system. By comparing a chromatograph of the products with that of standard substances, it was found that there were two arsenic species, monomethylarsenic $(\mathrm{V})$ and inorganic $\operatorname{arsenic}(\mathrm{V})$, in the reaction system. Inorganic arsenic $(V)$ was obtained by the oxidation of the reactant inorganic arsenic(III). From these observations, it can then be seen that monomethylarsenic was the only product of this methylation reaction; there were no other methylarsenic products.

Being a strong oxidant, $\mathrm{H}_{2} \mathrm{O}_{2}$ can terminate the methylation reaction of arsenic by oxidizing arsenic from As(III) to As(V), and cannot transform methylarsenic into any other species. It was, therefore, used as a termination solvent of methylation reaction. The volume of $\mathrm{H}_{2} \mathrm{O}_{2}$ was optimized and was shown in Fig. 3. With the volume of $\mathrm{H}_{2} \mathrm{O}_{2}$ increasing, all trivalent inorganic arsenic was oxidized into pentavalent arsenic. A volume of $300 \mu \mathrm{l} \mathrm{H}_{2} \mathrm{O}_{2}$ was enough to ensure that all $\mathrm{As}$ (III) was converted into $\mathrm{As}(\mathrm{V})$ in the samples. Therefore, $300 \mu \mathrm{l}$ of $\mathrm{H}_{2} \mathrm{O}_{2}$ was selected as the optimal volume of termination solvent.

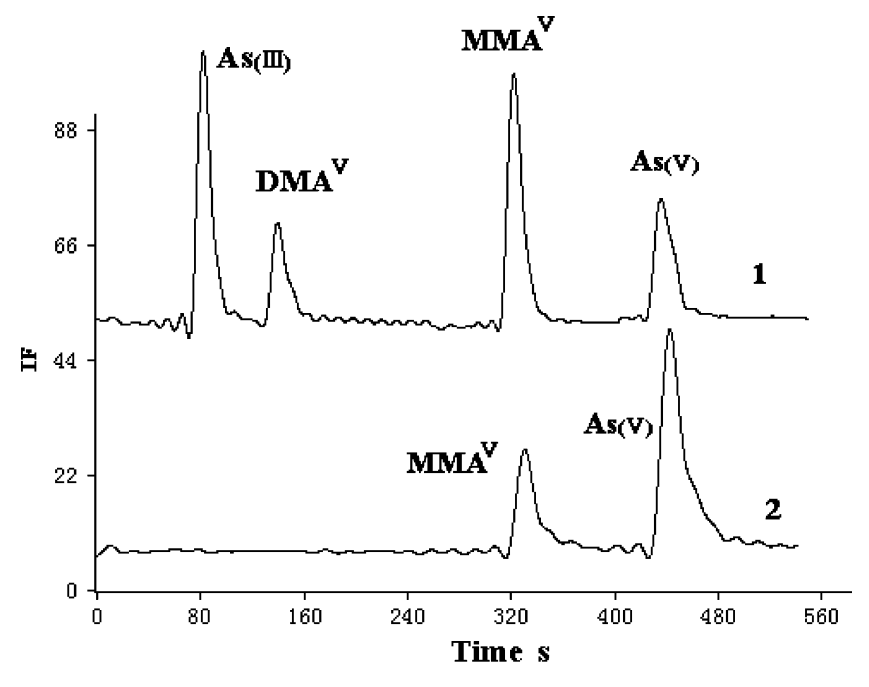

Figure 2. HPLC-HG-AFS chromatograph of arsenic compounds in the water. 1, Standard substances; 2, sample from reaction system.

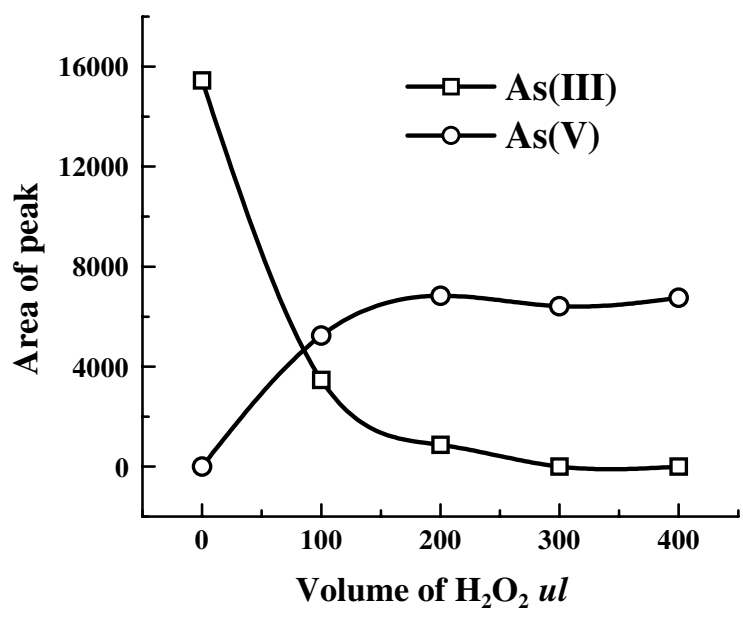

Figure 3. Optimization of the volume of $\mathrm{H}_{2} \mathrm{O}_{2}$ as reaction termination solvent.

The influences of $\mathrm{pH}$ and salinity of the reaction system on the methylation reaction of arsenic were also studied. The effect of $\mathrm{pH}$ on the methylation reaction of arsenic appeared in Fig. 4. Clearly, the methylation reaction from inorganic As(III) to monomethylarsenic(V) cannot happen in acidic, neutral and weak basic solution; it can only take place in strong basic conditions. This experimental result may be explained by the standard redox potential of arsenic in aqueous solutions. In acidic conditions, the standard redox potential of $\mathrm{H}_{3} \mathrm{AsO}_{4}(\mathrm{~V}) / \mathrm{HAsO}_{2}(\mathrm{III})$ is $0.559 \mathrm{~V}$. Nevertheless, the standard redox potential of $\mathrm{AsO}_{4}{ }^{3-}(\mathrm{V}) / \mathrm{AsO}_{2}{ }^{-}$(III) is $-0.67 \mathrm{~V}$ in basic solutions. From the standard redox potential, it was judged that inorganic As(III) is more easily subjected to oxidative methylation in basic conditions than in acidic 


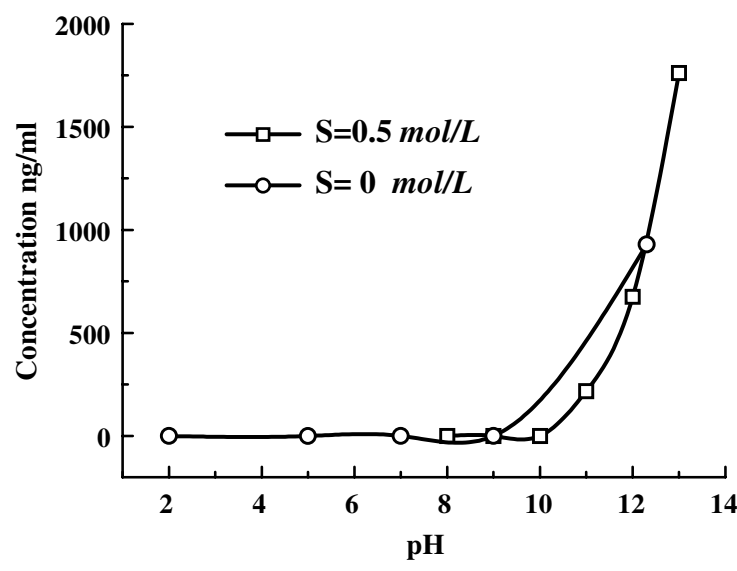

Figure 4. The effect of $\mathrm{pH}$ on the methylation reaction of arsenic.

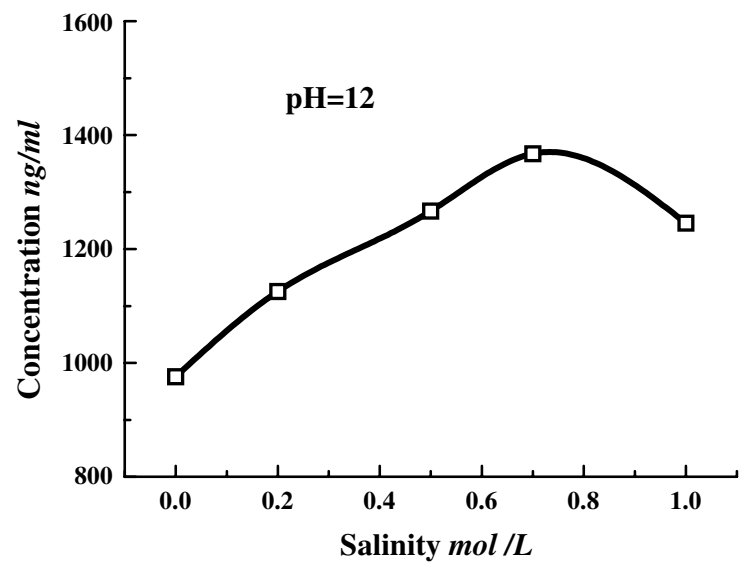

Figure 5. The effect of salinity on the methylation reaction of arsenic.

conditions, which is in agreement with our experimental result. Tin was also found to have higher methylation activity with $\mathrm{MeI}$ in basic solution than that in acidic solution because of the difference in its redox potential. ${ }^{19}$ In conclusion, the redox potential of a metal ion in aquatic solution is a very important factor for its methylation.

The effect of the salinity on methylation of arsenic was depicted in Fig. 5. With the increase in salinity, the concentration of monomethylarsenic in the reaction system increased in the beginning, and then decreased after the salinity had reached $0.75 \mathrm{~mol} \mathrm{l}^{-1}$. A probable reason for the effect of the salinity on arsenic methylation is that the salinity influences the activity of the methyl donors in aquatic solution.

Paul et al. used a quantum chemical method to estimate the thermodynamic parameters of the methyl arsenic species. ${ }^{16}$ The thermodynamic plausibility of methylation reaction can then be analyzed using the estimated Gibbs free energies. A derivation for the first methylation-oxidation step from

Copyright (c) 2006 John Wiley \& Sons, Ltd. inorganic arsenic to monomethylarsenic proceeded from reaction (1):

$$
\mathrm{As}(\mathrm{OH})_{3}+\mathrm{CH}_{3}{ }^{+} \longrightarrow \mathrm{CH}_{3} \mathrm{AsO}(\mathrm{OH})_{2}+\mathrm{H}^{+}
$$

As result, the reaction free energy change associated with the methylation-oxidation reaction $\Delta G_{\mathrm{rxn}}(\mathrm{M})$ will be:

$$
\begin{aligned}
& \Delta G_{\mathrm{rxn}}(\mathrm{M})=\Delta G_{\mathrm{f}}^{\circ}\left[\mathrm{CH}_{3} \mathrm{AsO}(\mathrm{OH})_{2}\right] \\
& -\Delta G_{\mathrm{f}}^{\circ}\left[\mathrm{As}(\mathrm{OH})_{3}\right]-1.36\left(\mathrm{pH}-\mathrm{pCH}_{3}{ }^{+}\right)
\end{aligned}
$$

It can obviously be seen, from equation (2), that the methyl donor activity $\left(-\mathrm{pCH}_{3}{ }^{+}\right)$and $\mathrm{pH}$ are the two most important factors for methylation of arsenic. A large $-\mathrm{pCH}_{3}{ }^{+}$ represents a high level of activity of the methyl donor. From a thermodynamic point of view, the reaction free energy change $\Delta G_{r x n}(M)$ will decrease with the increase in $\mathrm{pH}$ and $-\mathrm{pCH}_{3}{ }^{+}$, and the methylation reaction of inorganic arsenic is thermodynamically favorable. This explains why methylarsenic can gradually be detected with the $\mathrm{pH}$ of the reaction system rising, and the change of the salinity leads to the change in methylation efficiency of As(III).

Kinetic experiments were also performed in different conditions of salinity, $\mathrm{pH}$ and volume of $\mathrm{MeI}$ (Figs 6-8). The slope of the tangent at kinetic curves represents the reaction rate at that time point. Therefore, we can observe that the slope of the kinetic curve decreases with longer reaction time, which means that the rate of the methylation reaction drops. $\mathrm{pH}$, salinity and volume of MeI all had strong influences on the kinetic of methylation reaction.

$$
\mathrm{As}(\mathrm{OH})_{3}+\mathrm{CH}_{3}{ }^{+} \mathrm{I}^{-} \longrightarrow \mathrm{CH}_{3} \mathrm{AsO}(\mathrm{OH})_{2}+\mathrm{HI}
$$

For equation (3), the rate of methylation can be expressed as

$$
\frac{\mathrm{d}\left[\mathrm{CH}_{3} \mathrm{AsO}(\mathrm{OH})_{2}\right]}{\mathrm{d} t}=k\left[\mathrm{CH}_{3}{ }^{+} \mathrm{I}^{-}\right]^{n}\left[\mathrm{As}(\mathrm{OH})_{3}\right]^{m}
$$

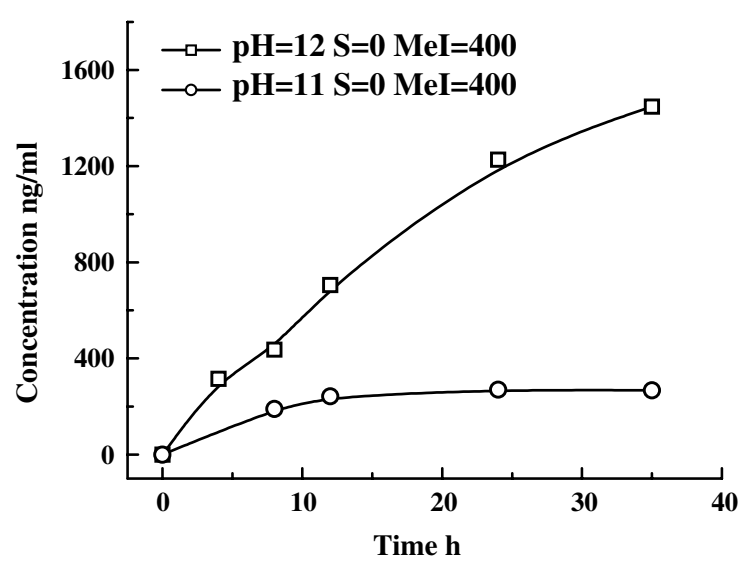

Figure 6. Kinetic curves at different $\mathrm{pH}$ values. 


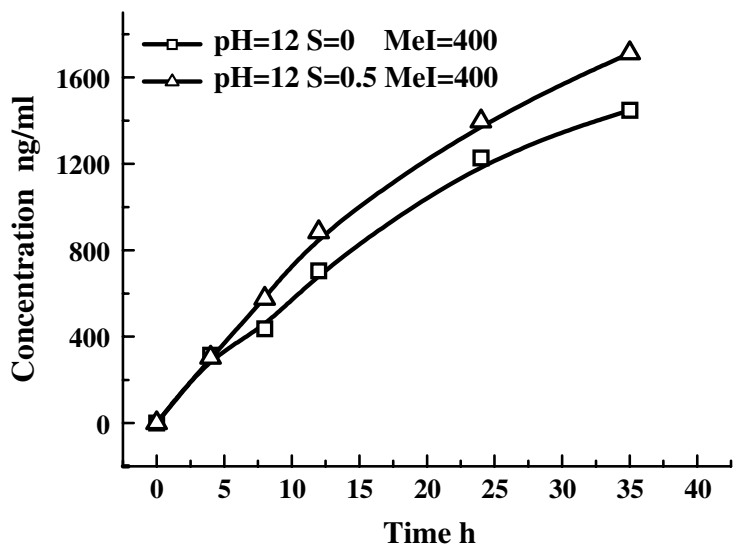

Figure 7. Kinetic curves at different salinities.

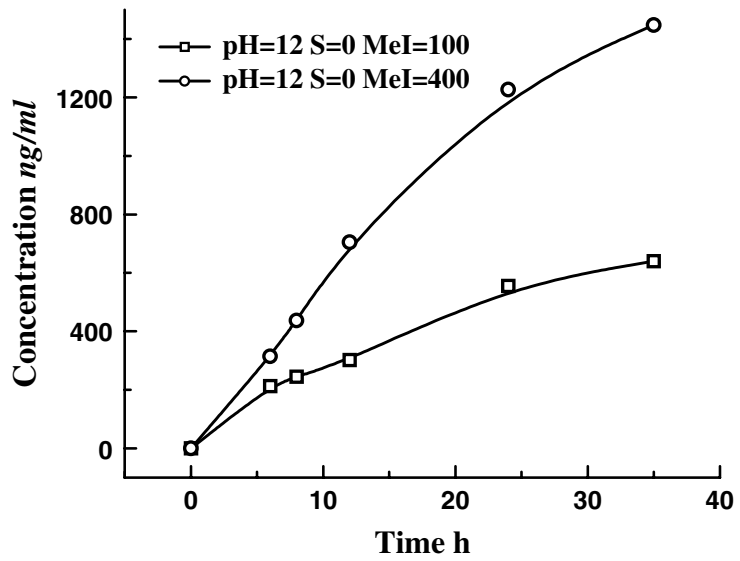

Figure 8. Kinetic curves at different volumes of Mel.

Because a large excess of $\mathrm{CH}_{3} \mathrm{I}$ over $\mathrm{As}(\mathrm{OH})_{3}$ was used in all kinetic experiments, the methylation rate in equation (5) may be obtained from equation (4):

$$
\frac{\mathrm{d}\left[\mathrm{CH}_{3} \mathrm{AsO}(\mathrm{OH})_{2}\right]}{\mathrm{d} t}=k_{\mathrm{obs}}\left[\mathrm{As}(\mathrm{OH})_{3}\right]^{m}
$$

where $k_{\mathrm{obs}}$ is the observed rate constant. If $m=1$, the methylation reaction is pseudo-first-order for As(III), and equation (5) can then be expressed as:

$$
-\ln \frac{C_{0}-C}{C_{0}}=k_{\text {obs }} t
$$

In equation (6), $C_{0}$ is the initial concentration of $\mathrm{As}(\mathrm{III})$ and $C$ is the concentration of monomethylarsenic.

The first-order kinetics of methylation reactions under different conditions were confirmed by plotting $-\ln \left[\left(C_{0}-\right.\right.$ C) $/ C_{0}$ ] vs reaction time, which yielded a straight line. The results of the first-order fit were shown in Figs 9-11. The correlation coefficients $R$ of the first-order fit of kinetic curves was in the range $0.91-0.98$, which demonstrated that methylation reaction of inorganic arsenic with MeI has a good Copyright (c) 2006 John Wiley \& Sons, Ltd.

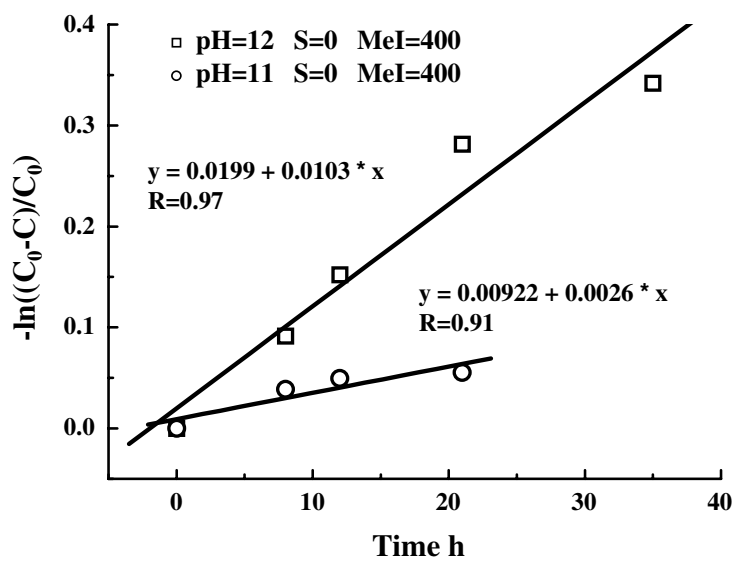

Figure 9. First-order rate plots at different $\mathrm{pH}$ values.

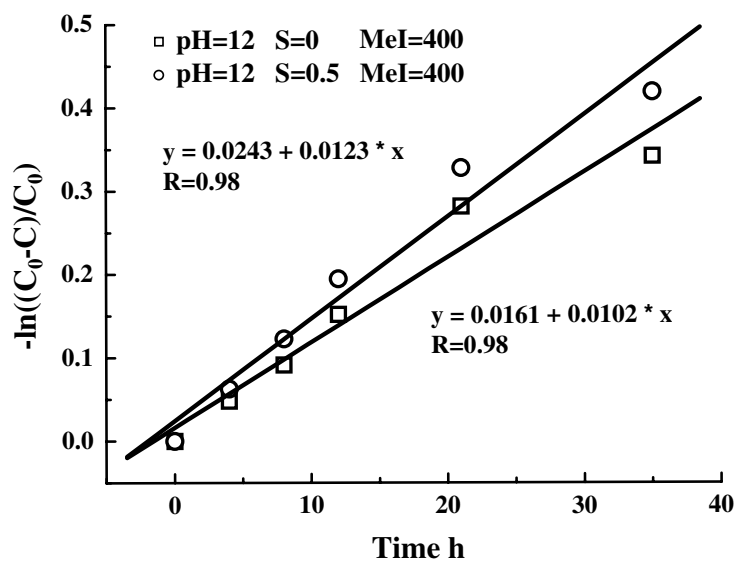

Figure 10. First-order rate plots at different salinities.

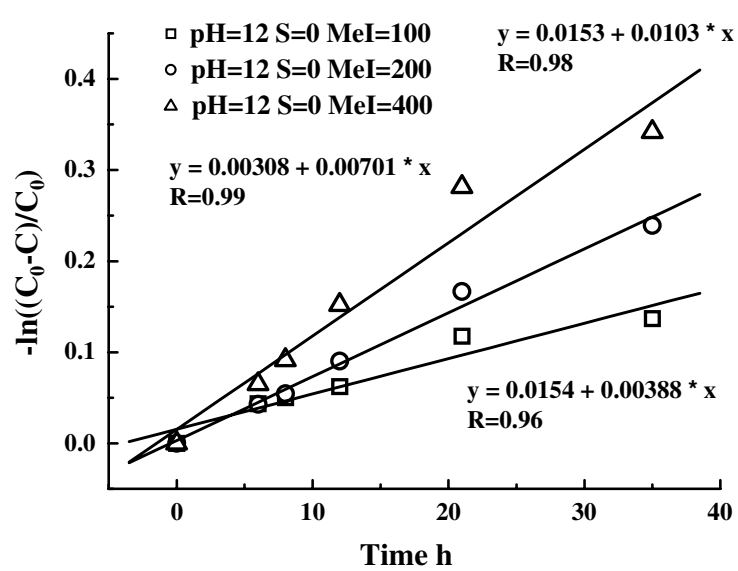

Figure 11. First-order rate plots at different volumes of Mel.

correlation with the first-order reaction kinetics for As(III). The rate of the first-order reactions ranged from 0.0026 to $0.0123 \mathrm{~h}^{-1}$, and varied greatly with the change in reaction 


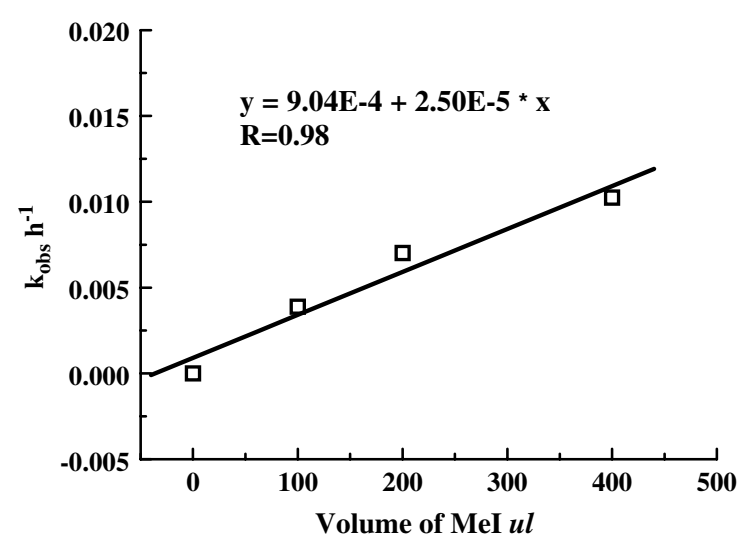

Figure 12. Plot of first-order reaction rate vs volume of Mel.

condition. The reaction rate rose from $0.0026 \mathrm{~h}^{-1}$ at $\mathrm{pH}=11$ to $0.0103 \mathrm{~h}^{-1}$ at $\mathrm{pH}=12$, with $S=0$ and $\mathrm{MeI}=400 \mu \mathrm{l}$. Under the condition of $\mathrm{pH}=12$ and $\mathrm{MeI}=400 \mu \mathrm{l}$, the reaction rate increased from 0.01025 to $0.0123 \mathrm{~h}^{-1}$ when the salinity of reaction system rose from 0 to $0.5 \mathrm{~mol}^{-1}$. Furthermore, the methylation rate increased with the rise of volume in MeI at constant salinity and $\mathrm{pH}: 0.00388 \mathrm{~h}^{-1}$ at $\mathrm{MeI}=100 \mu \mathrm{l}$, $0.00701 \mathrm{~h}^{-1}$ at $\mathrm{MeI}=200 \mu \mathrm{l}$ and $0.0103 \mathrm{~h}^{-1}$ at $\mathrm{MeI}=400 \mu \mathrm{l}$, respectively.

Under pseudo-first-order conditions with varying volume of MeI added into the reaction system, a good linear relation of $k_{\mathrm{obs}}$ vs volume of MeI (the concentration of MeI in methylation system) can also be obtained, which was shown in Figure 12. The relation can be express as:

$$
k_{\mathrm{obs}}=k_{1}+k_{2} V_{\mathrm{MeI}}
$$

where the intercept $k_{1}=9.04 \times 10^{-4} \mathrm{~h}^{-1}$; slope $k_{2}=2.50 \times$ $10^{-5} \mathrm{\mu l}^{-1} \mathrm{~h}^{-1} ; V_{\text {MeI }}$ is the volume of MeI. The correlation coefficient $R$ was 0.98 . This provided evidence that the methylation reaction was also first-order for MeI.

In aquatic environments, methyl iodide acted as the donor of carbonium and can react with inorganic As(III) to produce monomethylarsenic. In our reaction system, no other compounds except for methyl iodide can oxidize $\mathrm{As}(\mathrm{III})$ to $\mathrm{As}(\mathrm{V})$. Therefore, this methylation reaction was a mechanism of oxidative methyl-transfer. However, this chemical methylation reaction only happens under basic conditions because the redox potential of inorganic arsenic is $\mathrm{pH}$-dependent. The redox potential is closely related to the thermodynamics of methylation reaction existing in the aquatic environments.

There have been many reports on the methylation reaction of arsenic in organisms. ${ }^{7,8}$ Challenger demonstrated that $S$-adenosylmethionine (SAM) plays an important role in biomethylation of arsenic, and can transfer the methyl group of methionine to arsenic. ${ }^{21}$ These findings suggest that there must be some kind of enzyme acting as the catalyst of the biomethylation reaction, which means that biological methylation is completed at the $\mathrm{pH}$ of the organism, which is generally close to 7 . Further study is necessary to confirm which enzymes in the organism take part in the biomethylation reaction.

\section{CONCLUSION}

HPLC-HG-AFS was applied in studying the methylation reaction of arsenic in aquatic environments because it provided good and rapid separation of soluble methylarsenic with high sensitivity. Monomethylarsenic was the only product of the methylation reaction of inorganic As(III) with methyl iodide. In our experiments, this reaction can only occur in basic solution. The mechanism can be described as an oxidative carbonium transfer. The $\mathrm{pH}$ value had a major influence on methylation because the redox potential of $\mathrm{As}(\mathrm{III})$ was dependent on the $\mathrm{pH}$ of the solution. The redox potential switch was important for the methylation of a metal ion in the aquatic environment. The concentration of methyl donor and the salinity had a major influence on the methylation reaction because they affect the activity of methyl donors in the aquatic environment. Moreover, methylation reaction had good correlation with first-order reaction kinetics for both $\mathrm{As}(\mathrm{III})$ and methyl iodide. Firstorder reaction rates were computed at different $\mathrm{pH}$, salinity and $\mathrm{MeI}$ concentration, and were found to be in the range $0.0026-0.0123 \mathrm{~h}^{-1}$.

\section{Acknowledgments}

This work was jointly supported by the National Natural Science Foundation of China (20477053) and the National Basic Research Program of China (2003CB415001 and 2005CB422206)

\section{REFERENCES}

1. Hamasaki T, Nagase H, Yoshioka Y, Sato T. Formation, distribution, and ecotoxicity of methylmetals of tin, mercury, and arsenic in the environment. Crit. Rev. Environ. Sci. Technol. 1995; 25: 45.

2. Guha Mazumder DN, Das Gupta J, Santra A, Pal A, Ghose A, Sarkar S. J. Ind. Med. Assoc. 1998; 96: 4.

3. Challenger F, Higginbottom C, Ellis L. J. Chem. Soc. 1933; 1933: 95.

4. Challenger F. Chem. Rev. 1945; 36: 315.

5. McBride BC, Wolfe RS. Biochemistry 1971; 10: 4312. DOI: 10.1021/bi00799a024.

6. Cullen WR, McBride BC, Pickett AW. Appl. Organomet. Chem. 1990; 4: 119. DOI: 10.1002 /aoc.590040206.

7. Riedel GF, Sanders JG, Osman RW. J. Exp. Mar. Biol. Ecol. 1989; 134: 143.

8. Braman RS, Foreback CC. Science 1973; 182: 1247.

9. Akagi H, Fujita M, Sakagami Y. Eisei Kagaku 1972; 18: 309.

10. Akagi H, Sakagami Y. Eisei Kagaku 1972; 18: 358.

11. Guo XM, Sturgeon RE, Mester Z, Gardner GJ. J. Anal. At. Spectrom. 2005; 20: 702. DOI: 10.1039/b503661e.

12. McSheehy S, Guo XM, Sturgeon RE, Mester Z. J. Anal. Atom. Spectrom. 2005; 20: 709. DOI: 10.1039/b503662c. 
13. Ashby JR, Craig PJ. Sci. Total Environ. 1991; 100: 337. DOI: 10.1016/0048-9697(91)90384-Q.

14. Celo V, Lean DRS, Scott SL. Sci. Total Environ. 2005 (in press). DOI:10.1016/j.scitotenv.2005.09.043.

15. Bentley R, Chasteen TG. Microbiol. Mol. Biol. Rev. 2002; 66: 250. DOI: 10.1128/MMBR.66.2.250-271.2002.

16. Paul MD, Wei L, Kevin JF, John DM, Dominic MDT. Environ. Sci. Technol. 2005; 39: 2169. DOI: 10.1021/es0489691.
17. Gschwend PM, MacFarlane JK, Newman KA. Science 1985; 227: 1033.

18. Lovelock JE. Nature 1975; 256: 193. DOI: 10.1038/256193a0.

19. Chen BW, Jiang GB, Yang RQ, Liu JY. Appl. Organometal. Chem. 2006; 20: 161. DOI: 10.1002/aoc.1032.

20. Yuan CG, Jiang GB, He B. J. Anal. Atom. Spectrom. 2005; 20: 103. DOI: $101039 / \mathrm{b} 416102 \mathrm{e}$.

21. Challenger F, Lisle DB, Dransfield PB. J. Chem. Soc. 1954; 2: 1760. 